\title{
RESEARCH
}

Open Access

\section{Alcohol consumption and its associated factors among pregnant women in Sub- Saharan Africa: a systematic review and meta-analysis' as given in the submission system}

Alemu Earsido Addila ${ }^{1,2^{*}}$, Telake Azale Bisetegn ${ }^{3}$, Yigzaw Kebede Gete ${ }^{2}$, Mezgebu Yitayal Mengistu ${ }^{4}$ and Getnet Mihretie Beyene $e^{2,5}$

\begin{abstract}
Background: Alcohol consumption during pregnancy represents a significant public health concern. It has several adverse health effects for both the mother and the developing fetus. This study aimed to estimate the pooled prevalence and the effect size of associated factors of alcohol consumption during pregnancy in Sub-Saharan Africa countries.

Methods: The results of the review were reported based on the Preferred Reporting Items for Systematic Review and Meta-Analysis statement (PRISMA) guideline and, it was registered in the Prospero database, number CRD42019127103. The available primary studies were collated from different databases: PubMed, CINAHL, Cochrane Library, PsycINFO, Google Scholar, African Journals Online and Centre for Addiction and Mental Health Library. The main search terms were [((alcohol consumption) OR (alcohol drinking) OR (alcohol use) OR (ethanol use) OR (alcohol exposure)) AND ((pregnant women) OR (pregnant mother) OR (during pregnancy)) AND (Sub-Saharan Africa)]. We used the Joanna Briggs Institute (JBI) for critical appraisal of studies. The random-effects model was computed to estimate the pooled prevalence. Heterogeneity between studies was checked using the $\mathrm{I}^{2}$ statistic and the Cochrane $\mathrm{Q}$ test.

\footnotetext{
* Correspondence: alexisersid@gmail.com

'Department of Public Health, College of Medicine and Health Sciences,

Wachemo University, Hossana, Ethiopia

${ }^{2}$ Department of Epidemiology and Biostatistics, Institute of Public Health,

College of Medicine and Health Sciences, University of Gondar, Gondar,

Ethiopia

Full list of author information is available at the end of the article
}

C C The Author(s). 2020 Open Access This article is licensed under a Creative Commons Attribution 4.0 International License, which permits use, sharing, adaptation, distribution and reproduction in any medium or format, as long as you give appropriate credit to the original author(s) and the source, provide a link to the Creative Commons licence, and indicate if changes were made. The images or other third party material in this article are included in the article's Creative Commons licence, unless indicated otherwise in a credit line to the material. If material is not included in the article's Creative Commons licence and your intended use is not permitted by statutory regulation or exceeds the permitted use, you will need to obtain permission directly from the copyright holder. To view a copy of this licence, visit http://creativecommons.org/licenses/by/4.0/ The Creative Commons Public Domain Dedication waiver (http://creativecommons.org/publicdomain/zero/1.0/) applies to the data made available in this article, unless otherwise stated in a credit line to the data. 


\begin{abstract}
(Continued from previous page)
Results: The review resulted in 963 original studies after searching various databases, and finally 37 studies in qualitative synthesis and 30 articles in the systematic review and meta-analysis were included. The overall summary estimate of the prevalence of alcohol consumption during pregnancy was found to be $20.83 \%$ (95\% Cl: 18.21 , 23.46). The pooled estimate of meta-analysis showed that depression (OR: 1.572; 95\% Cl: 1.34, 1.845), partners' alcohol use (OR: 1.32, 95\% Cl: 1.11, 1.57), knowledge on harmful effect of alcohol consumption (OR: 0.36, 95\% Cl: $0.29,0.45)$ and, unplanned pregnancy (OR: $2.33,95 \% \mathrm{Cl}: 1.17,4.63)$ were statistically significant factors with alcohol consumption during pregnancy.

Conclusions: The result showed that there was high alcohol consumption during pregnancy in Sub- Saharan Africa. Alcohol consumption during pregnancy was associated with depression, partners' alcohol use, unplanned pregnancy and knowledge of the harmful effects of alcohol consumption. Therefore, this will be a basis for public policy and resource allocation for prevention initiatives.
\end{abstract}

Keywords: Pregnant women, Alcohol consumption, Sub-Saharan Africa

\section{Background}

Maternal mortality is still a major public health challenge. Most of these deaths are preventable and related to modifiable risk behaviors. Alcohol drinking during pregnancy is one of the few preventable and adjustable risk factors for adverse pregnancy and birth outcomes [1,2].

Alcohol drinking during pregnancy represents a significant public health concern. It has several adverse health effects for both the mother and the developing fetus [3]. Because of this, there is no universally accepted safe amount and time of alcohol consumption during pregnancy. Almost all guidelines advocate for women who are pregnant or who want to conceive to abstain from any amount of alcohol consumption because it is a known teratogen and causes potential adverse effects on pregnancy and birth outcomes [4-9]. Alcohol consumption during pregnancy can cause miscarriage, stillbirth, premature birth, congenital malformations, intrauterine growth retardation, and low birth weight. It is also attributed to fetal alcohol spectrum disorders (FASDs), (a group of conditions related to alcohol exposure before birth characterized by a range of lifelong irreversible negative health impacts, like physical, behavioral, and intellectual disabilities); and a leading cause of non-genetic mental retardation and other neurodevelopment deficits [5, 8-11]. Some studies on the relationship between these risks and the amount of alcohol consumed suggest that low-to-moderate drinking does not result in the same outcomes as heavy drinking $[10,12]$. On the other hand, new findings advocate that a small amount of alcohol consumption during the second and third trimester is not harmful to the unborn baby [10, 13]. Generally, alcohol consumption during pregnancy is a common risk factor for the health of newborns and the mother.

Among many countries in the world, women who are living in Chad, Namibia, Uganda, and Ethiopia are the highest alcohol consumers which are ranging from 17.7 to $24.5 \mathrm{l}$ of pure alcohol per capita per year [14-16]. Different studies conducted in various settings in Africa countries reveal that the prevalence of alcohol consumption during pregnancy varies from $2.5 \%$ [17] to $59.28 \%$ [18] which shows that a great discrepancy across different geographical settings and at different periods. In Sub-Saharan Africa, a great number of unplanned pregnancy [19], lack of awareness about the effect of alcohol consumption [20], having partners and friends consume alcohol $[19,21]$, some health-related problems like depression [22] and unemployment [19] are the main factors for alcohol consumption during pregnancy. The results showed that questionable reports on the magnitude of alcohol consumption and its associated factors during pregnancy. Moreover, there is no recent representative pooled data on alcohol consumption during pregnancy in Sub-Saharan Africa. Systematic reviews and meta-analysis were previous computed in the WHO African Region, however, things are dynamic and updated information is very essential for policy-makers and program-implementers. In order to take appropriate action, estimating the pooled magnitude and identifying factors influencing alcohol consumption are very crucial. Therefore, this systematic review and meta-analysis aimed to estimate the pooled prevalence and the effect size of associated factors of alcohol consumption during pregnancy in Sub-Saharan Africa countries.

\section{Methods}

Preferred Reporting Items for Systematic Review and Meta-Analysis statement (PRISMA) flow diagram and checklist were applied for designing and reporting the procedure [23] and, it was registered in the Prospero database, number CRD42019127103 (available at https:// www.crd.york.ac.uk/PROSPERO/\#myprospero).

\section{Eligibility criteria}

Cross-sectional, case-control, and cohort studies were included in the review. Studies that had reported the prevalence and/or at least one associated factor of 
alcohol consumption during pregnancy and were published in the English language from November 2009 to January 30, 2020, considered for review. Any amount of alcohol drinking during pregnancy and its risk factors were considered. Articles without abstracts and/or full text, and where there was the difficulty of extracting data were excluded from the analysis.

\section{Searching strategy and data sources}

Primary studies were collated from different databases (PubMed, CINAHL, Cochrane Library, PsycINFO, Google Scholar, Global Index Medicus, EMBASE, African Journals Online (AJOL) and Centre for Addiction and Mental Health Library).

The following search key terms were used by combing: "alcohol consumption"," alcohol drinking", alcohol use", pregnant women"," pregnant mother", "prenatal", "prevalence", "frequency", "occurrence", "epidemiology", "determinant factors", "associated factors", "influencing factors"," predictors", "contributing factors" and "Sub-Saharan Africa"(all Sub-Saharan Africa countries were entered turn by turn). Using all those terms, the search strategies were developed using different Boolean operators like 'AND' and 'OR' and MeSH Terms accordingly. The main search terms were [((alcohol consumption) OR (alcohol drinking) OR (alcohol use) OR (ethanol use) OR (alcohol exposure)) AND ((pregnant women) OR (pregnant mother) OR (during pregnancy)) AND (Sub-Saharan Africa)] from PubMed. The search was conducted turn by turn in all (46 according to UN Development Program) Sub-Saharan Africa countries [24] besides the term "Sub-Saharan Africa".

\section{Study selection}

Two independent reviewers (A.E and G.M) screened titles, abstracts and full texts for inclusion which were exported through data manager Endnote 7 to identify relevant articles and to remove unnecessary duplications. The divergences between two reviewers (A.E and G.M) were managed by a discussion based on established criteria. The remaining articles were evaluated based on the title, language and study setting. After rejecting inappropriate titles, the relevant abstracts and full texts were thoroughly reviewed.

\section{Quality assessment}

The Joanna Briggs Institute (JBI) critical appraisal checklist was used to evaluate the quality of articles [25-27]. The checklist comprises of 8,10 , and 11 items for crosssectional, case-control and cohort studies, respectively. The assessments of both reviewers (A. E and G. M) were compared and thoroughly discussed before a decisive quality assessment was made.

\section{Data extraction}

The eligible studies were identified using a checklist, and the data were extracted using a structured format on a Microsoft Excel spreadsheet by two independent reviewers (A.E and G.M). After the extracted data were crosschecked; some data extraction processes were repeated because of disagreement between reviewers. The Microsoft Excel spreadsheet was used to extract the most relevant information for review which comprises of the name of the first author, year of the publication, the study country, the study design, the sample size, the study setting and the instrument used to get alcohol use data.

\section{Outcome variable}

The outcome of the study was alcohol consumption which was defined as the proportion of pregnant women who consumed any amount of alcohol during pregnancy.

\section{Statistical analysis}

We used a random-effects model to estimate the pooled prevalence of alcohol consumption during pregnancy. Because we assumed that the parameter of interest was not identical across studies and the variability between the observed proportions. Heterogeneity between studies was computed using the $\mathrm{I}^{2}$ statistic (amount of heterogeneity) and the Cochrane $\mathrm{Q}$ test (presence of heterogeneity). $\mathrm{I}^{2}$ values of 25,50 , and $75 \%$ were low, moderate, and high heterogeneity, respectively [28]. Sensitivity analysis was done to identify the effect of an influential study on the overall results of the study. Subgroup analysis was also conducted by study setting and country to see their contribution as the source of heterogeneity. Publication bias was assessed using Funnel plot asymmetry through visual inspection and Egger's test [29]. Data were analyzed using statistical software Stata version 14.0.

\section{Results}

A total of 963 articles were retrieved after a comprehensive search strategy from different databases. Majority of articles 384 (39.9\%) were found in PubMed (after duplicated articles were specifically taken out from the PubMed database) and the rest from other databases. In the process, 448 records remained after removing duplicated retrievals and of which 325 records were excluded after assessing titles and abstracts because they were found to be irrelevant and did not fulfill the eligibility criteria. Thorough assessment and screening of full texts were done for the remaining 123 articles. Of these, 86 records were rejected for the absence of clear methods, inappropriate measurement tools and unmet criteria set for the year of publication. Thirty-seven studies were included in the qualitative synthesis. Finally, 30 studies 
were eligible for systematic review and meta-analysis (Fig.1).

In the final review, articles were published from 10 countries among 46 countries were included. Of these studies, eleven studies were found from Ethiopia [13, 19, 30-38], nine articles were from South Africa [20, 22, 39-46], five articles were from Nigeria [18, 47-50], two studies were from Ghana [51, 52], one article was from Kenya [53], three articles were from Tanzania [54-56], two studies were from Uganda [21, 57] one study was from Burkina Faso [58], and one article was from Zambia [59]. Regarding the study designs, twenty-five (83\%) of them were cross-sectional, three studies $(3.5 \%)$ were cohort and three articles (3.5\%) were case-control. In all studies, alcohol consumption data were taken from the self-report of pregnant women, which means no data was collected using biomarkers or meconium tests. Lists of self-reporting questionnaires were: Alcohol Use Disorder Identification Test-Consumption (AUDIT-C) [22, 40, 55], Tolerance, Worried, Eye-opener, Amnesia and, K/Cut-down (TWEAK) [57], Alcohol Use Disorders Identification Test (AUDIT) [39, 41], Cutting down, Annoyance, Guilt, and Eye-opener (CAGE) [21], Alcohol Smoking and Substance Involvement Test
(ASSIST) [44, 50], Tolerance- Annoyed, Cut off, Eyeopening (T-ACE) [19], and 1-Question screen strategy [60]. Structured questionnaires were used in the rest of all studies $(64 \%)$ to screen alcohol consumption during pregnancy.

\section{Prevalence of alcohol consumption during pregnancy of primary studies}

A total of 30 studies with 17,908 participants were used for prevalence estimation. The review indicated that the prevalence of alcohol consumption among pregnant women varied widely across countries. The lowest prevalence $(4.3 \%)$ was found in a study carried out at Dessie referral hospital, Northeast Ethiopia [34], whereas the highest prevalence $(59.28 \%)$ was reported in research conducted at a tertiary hospital in South Nigeria [18]. The detailed description of the included articles had been shown in Table 1 .

\section{Associated factors explanation of original studies}

The studies indicated that alcohol consumption during pregnancy associated with three major themes in SubSaharan Africa: socioeconomic factors like educational

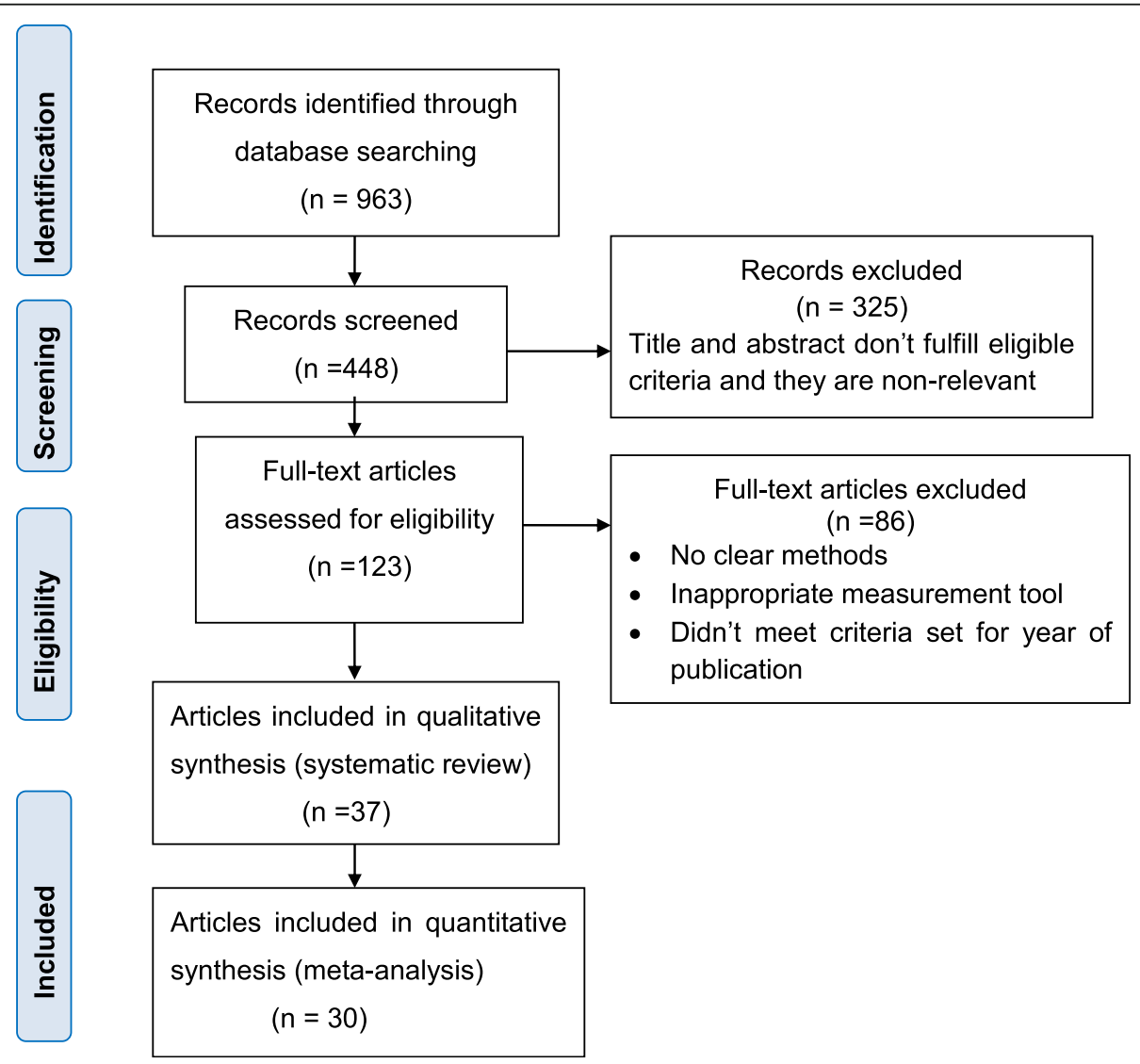

Fig. 1 Flow diagram showing the procedure of selecting studies on alcohol consumption during pregnancy for systematic review and metaanalysis, November 2009-January 2020, Sub-Saharan Africa 
Table 1 Characteristics of original studies included in systematic review and meta-analysis of alcohol consumption during pregnancy in Sub-Saharan Africa $(n=37)$

\begin{tabular}{|c|c|c|c|c|c|c|c|c|}
\hline s. no & Authors & $\begin{array}{l}\text { Study } \\
\text { country }\end{array}$ & $\begin{array}{l}\text { Publication } \\
\text { Year }\end{array}$ & Study design & Study setting & $\begin{array}{l}\text { Sample } \\
\text { size }\end{array}$ & $\begin{array}{l}\text { Prevalence } \\
\text { No (\%) }\end{array}$ & Data collection tool \\
\hline 1. & English LL [57] & Uganda & 2015 & Cohort & Community based & 505 & $81(16)$ & TWEAK questionnaire \\
\hline 2. & Namagembe, I [21]. & Uganda & 2010 & Cross sectional & Health facility based & 610 & $151(25)$ & CAGE questionnaire \\
\hline 3. & Mpelo, Matunga [55] & Tanzania & 2018 & Case-control & Health facility based & 365 & $55(15.1)$ & AUDIT-C questionnaire \\
\hline 4. & Mosha, T. C [54]. & Tanzania & 2010 & Cohort & Health facility based & 157 & $10(6.4)$ & Structured questionnaire \\
\hline 5. & Nombo, A [56]. & Tanzania & 2018 & Cross sectional & Health facility based & 609 & $77(12.6)$ & Standardized questionnaire \\
\hline 6. & Hartley, M [22]. & South Africa & 2011 & Cross sectional & Health facility based & 1062 & 295(27.8) & AUDIT-C questionnaire \\
\hline 7. & Myers, B [44] & South Africa & 2017 & Cross sectional & Health facility based & 667 & $148(22)$ & ASSIST questionnaire \\
\hline 8. & Bundree, S [43]. & South Africa & 2017 & Cohort & Community based & 759 & 139(18) & structured questionnaire \\
\hline 9. & Morojele, N [20]. & South Africa & 2010 & Cross sectional & Community based & 1018 & 292(28.7) & structured questionnaire \\
\hline 10. & Vythilingum, B [39]. & South Africa & 2012 & Cross sectional & Health facility based & 323 & $66(20.2)$ & AUDIT questionnaire \\
\hline 11. & Tomlinson, M [40]. & South Africa & 2014 & Cross sectional & Health facility based & 1145 & $284(25)$ & $\begin{array}{l}\text { AUDIT-C, structured } \\
\text { questionnaire }\end{array}$ \\
\hline 12. & Onah, M [42]. & South Africa & 2016 & Cross sectional & Health facility based & 376 & $52(13.8)$ & structured questionnaire \\
\hline 13. & Roos, A [41]. & South Africa & 2015 & Cross sectional & Health facility based & 148 & $43(29)$ & AUDIT questionnaire \\
\hline 14. & O'Connor, M.J [46]. & South Africa & 2011 & Cross sectional & Community based & 619 & $167(27)$ & $\begin{array}{l}\text { AUDIT-C, structured } \\
\text { questionnaire }\end{array}$ \\
\hline 15 & Ordinioha, B [18]. & Nigeria & 2015 & Cross sectional & Health facility based & 221 & 131(59.28) & Structured questionnaire \\
\hline 16. & Adebowale, O [50]. & Nigeria & 2018 & Cross sectional & Health facility based & 395 & $67(17)$ & $\begin{array}{l}\text { ASSIST/self-reporting } \\
\text { questionnaire }\end{array}$ \\
\hline 17. & Nyoyoko, N [48]. & Nigeria & 2016 & Cross sectional & Health facility based & 502 & 153(30.5) & semi-structured \\
\hline 18. & Onwuka, C [47]. & Nigeria & 2016 & Cross sectional & Health facility based & 380 & $86(22.6)$ & structured questionnaire \\
\hline 19. & Thompson,O [49]. & Nigeria & 2016 & Cross sectional & Health facility based & 294 & $17(5.8)$ & structured questionnaire \\
\hline 20. & Wagura,P [53]. & Kenya & 2018 & Cohort & Health facility based & 322 & $21(6.5)$ & standardized questionnaire \\
\hline 21. & Otupiri, E [51] & Ghana & 2012 & Cross sectional & Health facility based & 397 & $81(20.4)$ & structured questionnaire \\
\hline 22. & Lekettey, J [61]. & Ghana & 2017 & Cohort & Health facility based & 250 & $120(48)$ & Structured questionnaire \\
\hline 23. & Taye, M [33]. & Ethiopia & 2018 & Case-control & Health facility based & 414 & $67(19.3)$ & Structured questionnaire \\
\hline 24. & Anteab, K [19] & Ethiopia & 2014 & Case-control & Health facility based & 810 & $275(34)$ & $\begin{array}{l}\text { T-ACE, standardized } \\
\text { questionnaire }\end{array}$ \\
\hline 25. & Endashew, M [31]. & Ethiopia & 2015 & Cohort & Health facility based & 453 & 202(44.9) & Standardized questionnaire \\
\hline 26. & Grum,T [13]. & Ethiopia & 2017 & Cross sectional & Health facility based & 291 & $54(18.9)$ & structured questionnaire \\
\hline 27. & Aboye, W [32]. & Ethiopia & 2018 & Cross sectional & Health facility based & 308 & $50(16.2)$ & structured questionnaire \\
\hline 28. & Demelash,H [30]. & Ethiopia & 2015 & Cross sectional & Health facility based & 387 & $71(18.3)$ & Standardized questionnaire \\
\hline 29. & Tessema [34] & Ethiopia & 2015 & Cross sectional & Health facility based & 490 & $21(4.3)$ & structured questionnaire \\
\hline 30. & Hanlon [36] & Ethiopia & 2009 & Cohort & Community based & 1040 & $52(5)$ & Self-Reporting Questionnaire \\
\hline 31. & Terefa, T [35]. & Ethiopia & 2015 & Cross sectional & Community based & 340 & $86(25.3)$ & A semi-structured, \\
\hline 32. & Barthélémy, [62] & DR Congo & 2011 & Cross sectional & Community based & 240 & $78(32.5)$ & structured questionnaire \\
\hline 33. & Williams, A [60]. & Congo & 2013 & Cross sectional & Health facility based & 3099 & $722(23.3)$ & 1-Question screen \\
\hline 34. & Moise, I. K.et al. [59] & Zambia & 2019 & Cross sectional & Health facility based & 188 & $40(21.2)$ & $\begin{array}{l}\text { T-ACE, standardized } \\
\text { questionnaire }\end{array}$ \\
\hline 35. & Sanou, et al. [58] & Burkina Faso & 2017 & Cross sectional & Community based & 518 & $96(18.5)$ & $\begin{array}{l}\text { Self-Reporting Questionnaire } \\
\text { (yes/no) }\end{array}$ \\
\hline 36. & Wubetu. A et al. [38] & Ethiopia & 2019 & Cross sectional & Health facility based & 380 & $62(16.1)$ & CAGE questionnaire \\
\hline 37. & Mekuriaw B.et al. [37] & Ethiopia & 2019 & Cross sectional & Health facility based & 759 & $58(8.1)$ & AUDIT-C questionnaire \\
\hline
\end{tabular}


status, knowledge on harmful effects of alcohol use, source of income, and employment status; obstetric factors such as complications during previous pregnancies, marital status, pregnancy plan, and parity; and behavioral factors like prior alcohol consumption, partner's alcohol use, peer pressure on alcohol use, and smoking.

The review showed that post-primary educational status as compared to primary education (AOR 10.64, 95\% CI 1.89,19.84) [55], High School and TVET compared with illiterate women $(\mathrm{AOR}=2.70 ; 95 \% \mathrm{CI}: 1.25,5.81)$ [19], having Knowledge on harmful effect of alcohol use $(\mathrm{AOR}=0.37 ; 95 \%$ CI: $0.20,0.70)$ [20], $\mathrm{AOR}=3.26 ; 95 \%$ CI:1.79, 5.97) [47], making local brews as a source of income $(\mathrm{AOR}=11.444 ; 95 \% \mathrm{CI}: 1.01,19.86)$ [55], being unemployed (AOR $=3.11 ; 95 \% \mathrm{CI}: 1.73,5.60)$ [19] were predictors of alcohol consumption during pregnancy.

Regarding obstetric factors, not having complications in previous pregnancies $(\mathrm{AOR}=4.93 ; 95 \% \mathrm{CI}: 1.031$, 23.59) [55], being married ( $\mathrm{AOR}=3.09 ; 95 \% \mathrm{CI}: 1.79$, 5.33) [19], unplanned ( $\mathrm{AOR}=3.12$; 95\% CI: $1.85,5.28$ ) [19], $(\mathrm{OR}=1.9 ; 95 \% \mathrm{CI}: 1.06-3.4)$ [55], $(\mathrm{AOR}=2.12 ; 95 \%$ $\mathrm{CI}: 1.2,3.73)$ [37], and nulliparity ( $\mathrm{OR}=1.94 ; 95 \% \mathrm{CI}: 1.10$, 3.40) [47] were factors associated with alcohol consumption during pregnancy. On the other hand, prepregnancy alcohol consumption $(\mathrm{AOR}=5.19 ; 95 \% \mathrm{CI}$ : 4.791,34.87) [55], $(\mathrm{OR}=4.522) \quad$ [39], $(\mathrm{AOR}=1.94 ; 95 \%$ CI:1.18, 3.18) [47], (AOR $=2.17,95 \%$ CI: 1.18, 4.00) [37], alcohol consumption encouraged by somebody or having friends who use alcohol (AOR $=3.84 ; 95 \% \mathrm{CI}$ : 2.34, 6.30) [19], $(\mathrm{AOR}=1.57 ; 95 \% \mathrm{CI}: 1.39,6.25)$ [55], $(\mathrm{AOR}=2.36$; 95\% CI: 1.72, 3.23) [21], partner alcohol use $(\mathrm{AOR}=$ 1.71; 95\% CI:1.09, 2.67) [19], (AOR $=2.58$; 95\% CI: 1.12 , 5.97) [20], $(\mathrm{AOR}=1.56 ; 95 \% \mathrm{CI}: 1.21,2.02)$ [21], $(\mathrm{OR}=$ 4.87; 95\% CI: 2.64-8.997) [55], smoking ( $\mathrm{AOR}=2.92$; 95\% CI: 1.10, 7.79) [20], (AOR = 1.23; 95\% CI:1.15, 1.32) [21] were determinants of alcohol use during pregnancy.

Finally, pregnant mothers who were depressed more likely to drink alcohol than counterparts $(\mathrm{AOR}=5.1$; 95\% CI: 1.7,14.9) [49], (AOR = 1.6; 95\% CI:1.22, 2.1) [22], $(\mathrm{OR}=1.55)[40],(\mathrm{OR}=2.64)[42]$, and $(\mathrm{AOR}=1.91,95 \%$ $\mathrm{CI}=1.01,4.50)[38]$.

\section{Meta-analysis}

Meta-analysis was carried out for 30 articles (17,908 participants). The overall summary estimate of the prevalence of alcohol consumption during pregnancy was found to be $20.83 \%$ ( $95 \%$ CI: $18.21,23.46$ ) by the random effect model. I-squared result $\left(\mathrm{I}^{2}=95.0, p<0.001\right)$ showed that there was considerable heterogeneity among the included studies (Fig.2). Since the $P$-value for the $x^{2}$ test of heterogeneity was low $(<0.05)$, we conducted a subgroup analysis to make out the possible sources of the observed heterogeneity.

\section{Subgroup analysis}

We computed subgroup analysis based on study design, country and, study setting when at least two studies are in the same category. Accordingly, the lowest prevalence and heterogeneity of alcohol use during pregnancy were reported in case-control study design (Fig.3); the heterogeneity between the groups was not significant $(p=$ 0.642). Concerning the study setting and country, the heterogeneity was still appreciable in both subgroups. On the other hand, the highest prevalence of alcohol consumption during pregnancy was found in DR Congo $32.50 \%$ (95\%CI: 26.57, 38.43), whereas the lowest was remarked in Tanzania $13.45 \%$ (95\%CI: 11.31, 15.59) (Table 2).

\section{Sensitivity analysis}

Sensitivity analysis was performed to identify which single study most influenced all other studies. However, an overweight study was not seen.

\section{Publication bias}

It was assessed by using a funnel plot of visual inspection which was symmetrical distribution (Fig.4) and, Egger's regression test statistics $p$-value was 0.870 , which showed the absence of publication bias for estimating the prevalence of alcohol consumption during pregnancy.

\section{Factors associated with alcohol consumption during pregnancy}

Thirteen studies were screened which fulfilled the set criteria for factors associated with pregnant mothers alcohol use [19-22, 37-40, 42, 46, 47, 49, 63]. The result of the pooled estimate showed that depression, partners' alcohol use, knowledge on the harmful effects of alcohol consumption and unplanned pregnancy were statistically significant factors to influence alcohol consumption during pregnancy. On the other hand, cigarette smoking, pre-pregnancy alcohol drinking and having alcohol drinking friends were not statistically significant factors for alcohol use.

\section{Association between pregnant mothers and their partners' alcohol consumption}

According to the pooled effects of four studies [19-21, 63], the likelihood of pregnant women alcohol consumption was 1.32 times more likely to use alcohol whose partners consumed alcohol as compared to their counterparts (OR: 1.32, 95\% CI: 1.11, 1.57) (Fig. 5).

Furthermore, publication bias was checked using Begg's and Egger's tests. The results of these tests showed that there was no possible presence of statistically significant publication bias $(p=0.308$ and $0.174)$, respectively. 


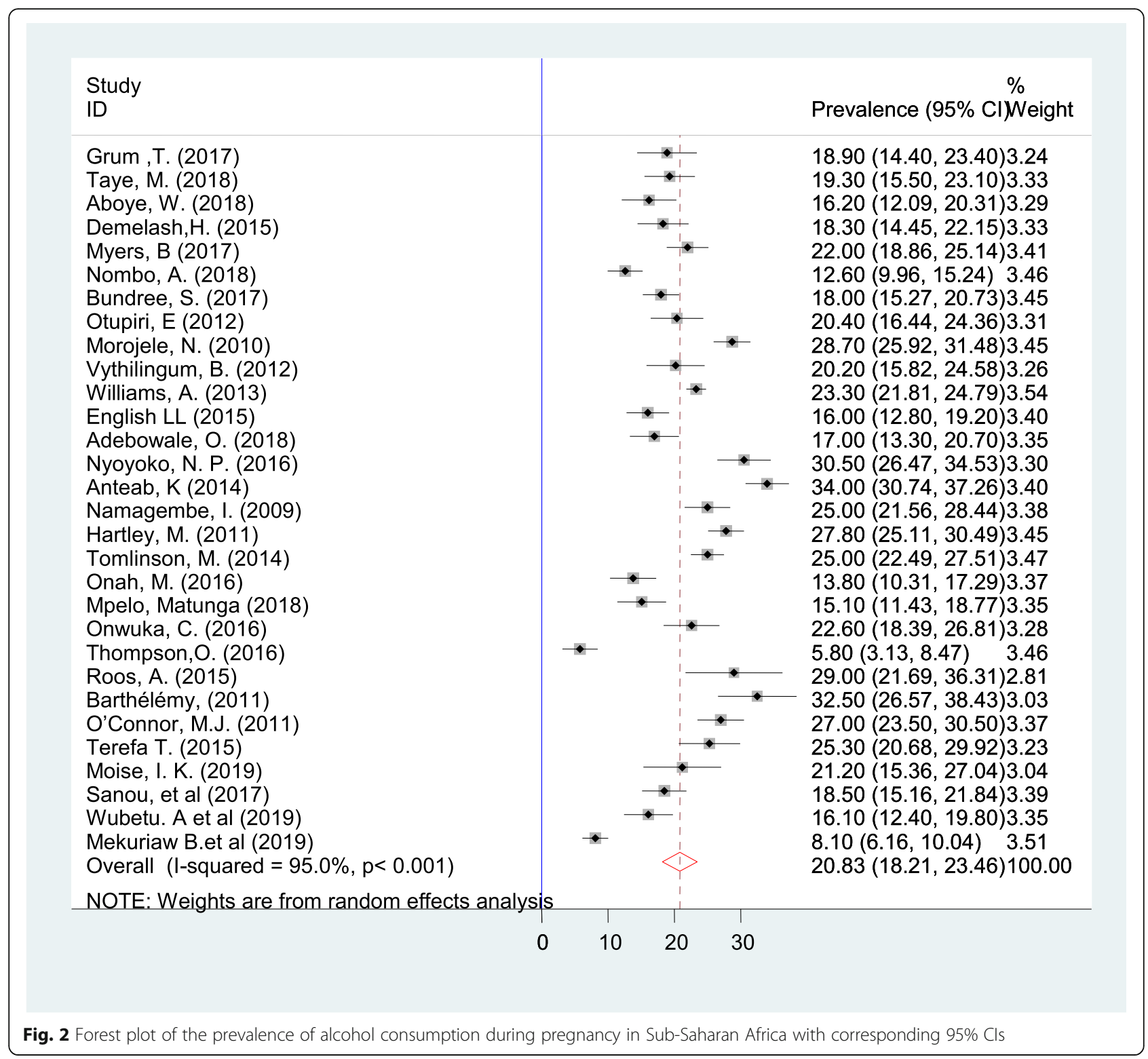

\section{Association between alcohol consumption of pregnant mothers and depression}

The review exhibited that depression was a statistically significant factor for alcohol consumption during pregnancy based on analysis conducted on five studies [22, 38, 40, 46, 49]. Pregnant women who were depressed almost 1.6 times more likely to use alcohol than their counterparts (OR: 1.572, 95\% CI: $1.34,1.85)$ with $\mathrm{I}^{2}=0.0 \%$ and $p$-value $\left.=0.98\right)$. Publication bias was visually examined using funnel plot and tested with Egger's weighted regression and Begg's rank correlation method. The result of these tests showed that there was no significant asymmetry ( $p=0.053$ and 0.086$)$, respectively (Fig. 6).

To determine the correlation between alcohol consumption of the pregnant mothers and their knowledge of the harmful effect of alcohol use on birth outcomes two studies were analyzed [20, 47]. Pregnant women who had awareness of the adverse effect of alcohol drinking during pregnancy on birth outcomes were $64 \%$ less likely to consume alcohol as compared to their counterparts (OR: 0.36, 95\% CI: $0.29,0.45)$ with $\left(\mathrm{I}^{2}=\right.$ $0.0 \%$ and $p=0.596)$. Women who had unplanned their pregnancy were twice more likely to drink alcohol as compared to those who had planned [19, 37, 55] (OR: 2.33, 95\% CI: $1.17,4.63)$ with $\left(\mathrm{I}^{2}=0.0 \%\right.$ and $\left.p=0.779\right)$. In addition, the pooled result of analysis indicated that drinking encouraged by friends or having alcohol drinking friends $[19,21,55]$ (OR: 1.78, 95\% CI: 0.79, 4.05) with $\left(\mathrm{I}^{2}=46.8 \%\right.$ and $\left.p=0.153\right)$, pre-pregnancy alcohol consumption [37, 39, 47, 55] (OR: 2.05, 95\% CI: 0.93, 


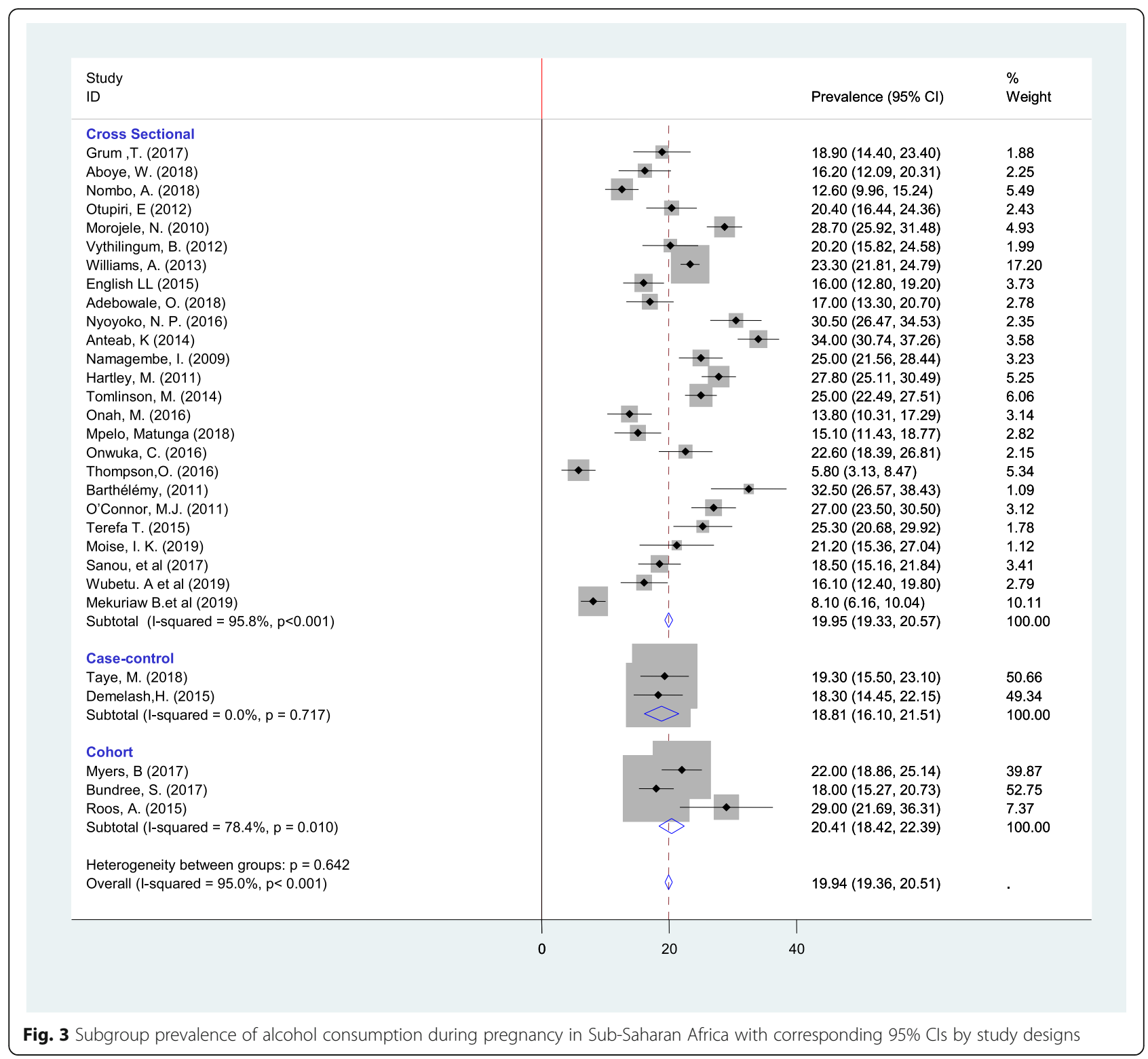

4.50) with $\left(\mathrm{I}^{2}=0.0 \%\right.$ and $\left.p=0.983\right)$, and cigarette smoking $[20,21,46]$ (OR: $2.37,95 \%$ CI: $0.70,7.99)$ with $\left(\mathrm{I}^{2}=\right.$ $83.3 \%$ and $p=0.002$ ) were not statistically significant factors for alcohol consumption.

\section{Discussion}

Despite the well known teratogenic adverse effect of alcohol consumption during pregnancy, several pregnant women use alcohol in Sub-Saharan Africa. Alcohol consumption during pregnancy is one of the modifiable health behaviors. Consumption of alcohol during pregnancy results in abortion-related maternal deaths and various fetal complications [1]. Pregnancy alcohol exposure (PAE) may serve as a proxy indicator of Fetal Alcohol Syndrome (FAS). To design pragmatic intervention, it is very vital to identify the women at high risk for using alcohol during pregnancy. In Sub-Saharan Africa, conducting this type of study will be paramount as input for policymakers and program planners working in the area.

We scanned 963 titles that were thoroughly specified to 37 publications for narrative synthesis and 30 studies for systematic review and meta-analysis. The search was retrieved from November 2009 to January 2020.

In this review, the prevalence of alcohol use during pregnancy varied within and across countries. For example, in Sub-Saharan Africa, the prevalence varied from 4.30 to $59.28 \%$, while in Ethiopia; it was 4.3 to $44.9 \%$. The variation might not be only due to maternal or individual drinking behaviors but also from environmental, genetic, 
Table 2 Summary of subgroup analysis of the prevalence of alcohol consumption during pregnancy in Sub-Saharan Africa, 2009Jan $2020(n=30)$

\begin{tabular}{|c|c|c|c|c|c|}
\hline Variables (subgroup) & Characteristics & Included studies & Pooled prevalence $(95 \% \mathrm{Cl})$ & $1^{2}$ & $P$-value \\
\hline \multirow[t]{3}{*}{ By design } & Cross- sectional & 25 & $18.81(16.10-21.50)$ & $95 \%$ & $<0.001$ \\
\hline & Case- control & 2 & $18.81(16.10-21.51)$ & $0.0 \%$ & 0.717 \\
\hline & Cohort & 3 & $20.41(18.42-22.39)$ & $78.4 \%$ & 0.010 \\
\hline \multirow[t]{2}{*}{ By study setting } & Health facility & 23 & 17.72(17.06-18.38) & $93.8 \%$ & $<0.001$ \\
\hline & Community & 7 & 26.77(25.61-27.93) & $87.3 \%$ & 0.001 \\
\hline \multirow[t]{10}{*}{ By country } & South Africa & 9 & $23.54(22.48,24.60)$ & $89.9 \%$ & $<0.001$ \\
\hline & Ethiopia & 8 & $16.79(15.62,17.97)$ & $96 . \%$ & $<0.001$ \\
\hline & Nigeria & 4 & 15.73(13.99-17.47) & $97.4 \%$ & $<0.001$ \\
\hline & Uganda & 2 & 20.18(11.31-15.59) & $92.9 \%$ & $<0.001$ \\
\hline & Tanzania & 2 & 13.45(11.31-15.59) & $14.9 \%$ & 0.278 \\
\hline & Zambia & 1 & $21.20(15.36,27.04)$ & . & . \\
\hline & Burkina Faso & 1 & $18.50(15.16,21.84)$ & . & \\
\hline & DR Congo & 1 & $32.50(26.57,38.43$ & . & . \\
\hline & Congo & 1 & $23.30(21.81,24.79)$ & . & \\
\hline & Ghana & 1 & $20.40(16.44,24.36)$ & & . \\
\hline
\end{tabular}

political, religious, policy and cultural differences [64]. The rate of alcohol consumption during pregnancy was very high in some studies $[18,19,31,52]$ due to several reasons like socialization with friends or peer pressure, lack of adequate information about the adverse health effect of PAE and having alcohol-consuming partners. This also could be because of the weak regulatory strategy of alcohol production, promotion, drinking pattern, and availability in every grocery and bar [65]. For example, in Ethiopia, "Areki", "Tella" and "Tej" are local alcoholic beverages that are produced and accessible everywhere [66]. Women's alcohol drinking has been increasing in line with economic growth, altering gender roles and increasing the social acceptability of women's alcohol consumption [67].

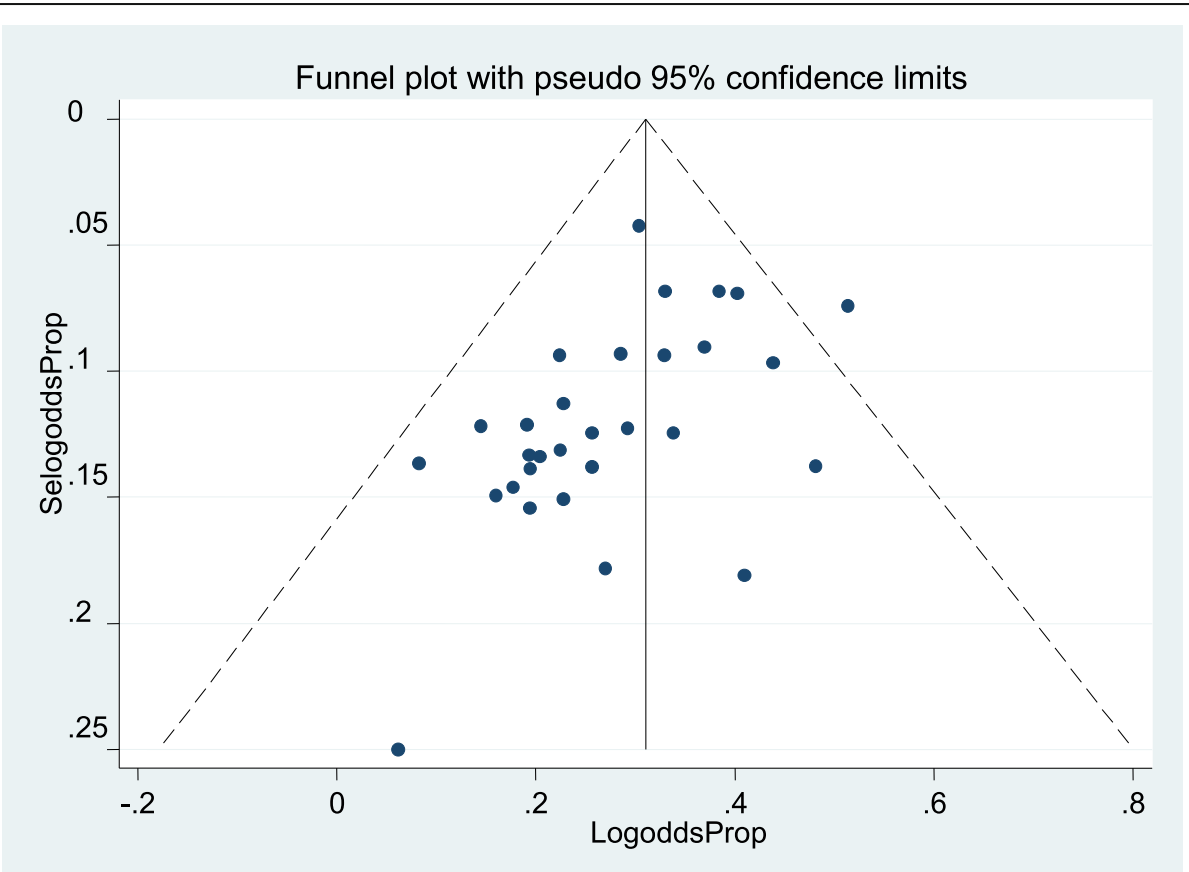

Fig. 4 Funnel plot depicts publication bias of alcohol consumption during pregnancy for systematic review and meta-analysis in Sub-Saharan Africa 


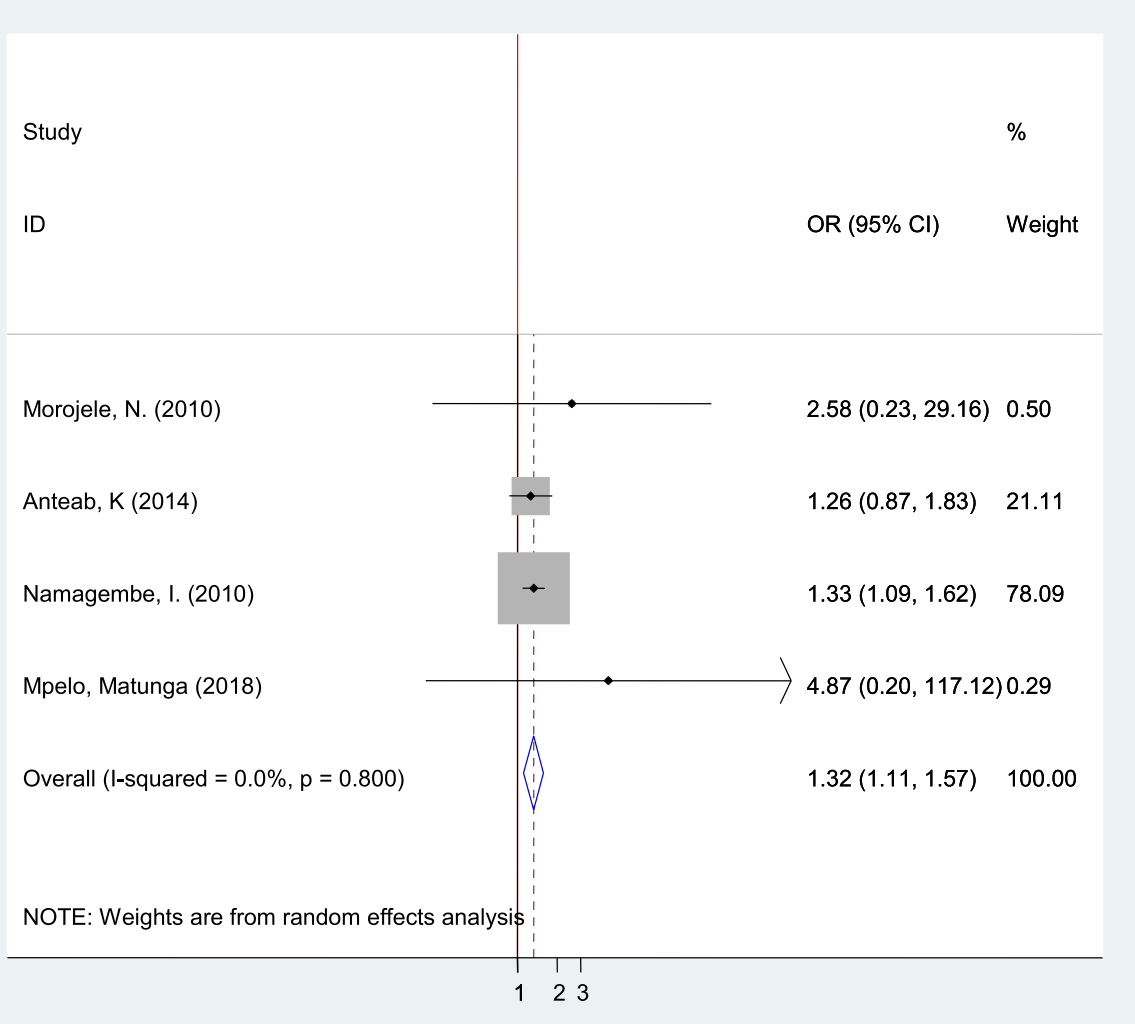

Fig. 5 The pooled odds ratio of the association between pregnant women and their partners' alcohol consumption in Sub-Saharan Africa

Accordingly, the pooled magnitude of alcohol consumption during the pregnancy was $20.83 \%$ (95\% CI: 18.21, 23.46). This result was greater than from findings of WHO Africa region 18.52\% [15], Korea 16.4\% [68], global estimated prevalence 9.8\% [69], and the Behavioral Risk Factor Surveillance System (BRFSS) surveys conducted by the Centers for Disease Control and Prevention in the United States the countrywide data between 2015 and 2017 11.5\% [70]. On the other hand, this figure was lower than studies done in Russia 25.5$60 \%$ [71, 72], and the report of prospective cohort studies and national surveys at various times in Australian 28-72\% [73-75]. The discrepancies between the drinking patterns of the pregnant mother might be associated with socioeconomic, cultural, health policy, sociodemographic, and alcohol drinkers screening tool differences. Determining the accurate prevalence and amount of alcohol consumption during pregnancy is very difficult since under-reporting is common because of social desirability bias, recall bias, religious beliefs and, seasonal and geographic variations $[76,77]$.

This result had indirectly shown that many pregnant women low adherence to alcohol guidelines which advising complete abstinence from alcohol use during pregnancy [4]. It might also show that there are many mothers and developing fetuses suffering from many adverse health effects in Sub-Saharan Africa associated with maternal alcohol use. A high number of pregnant women could unknowingly expose the developing fetus to alcohol.

Designing successful public health promotion policies relating to reducing alcohol consumption in pregnancy and preventing alcohol-exposed pregnancy requires an understanding of why women drink alcohol during pregnancy. This review showed that alcohol consumption during pregnancy was associated with three major themes in the original studies: socioeconomic factors like educational status, knowledge on harmful effects of alcohol use, source of income, and employment status; obstetric factors such as complications during previous pregnancies, marital status, pregnancy plan, and parity; and behavioral factors like prior alcohol consumption, partner's alcohol use, peer pressure on alcohol use, and smoking. However, in the meta-analysis, four variables had a statistically significant association with alcohol use during pregnancy. Depression was found to be a predictor of drinking during pregnancy in five studies [22, 38, 40, 46, 49]; this finding was consistent with the systematic review at the international level [78]. The result of some studies showed that various psychiatric symptoms like depression and alcohol 


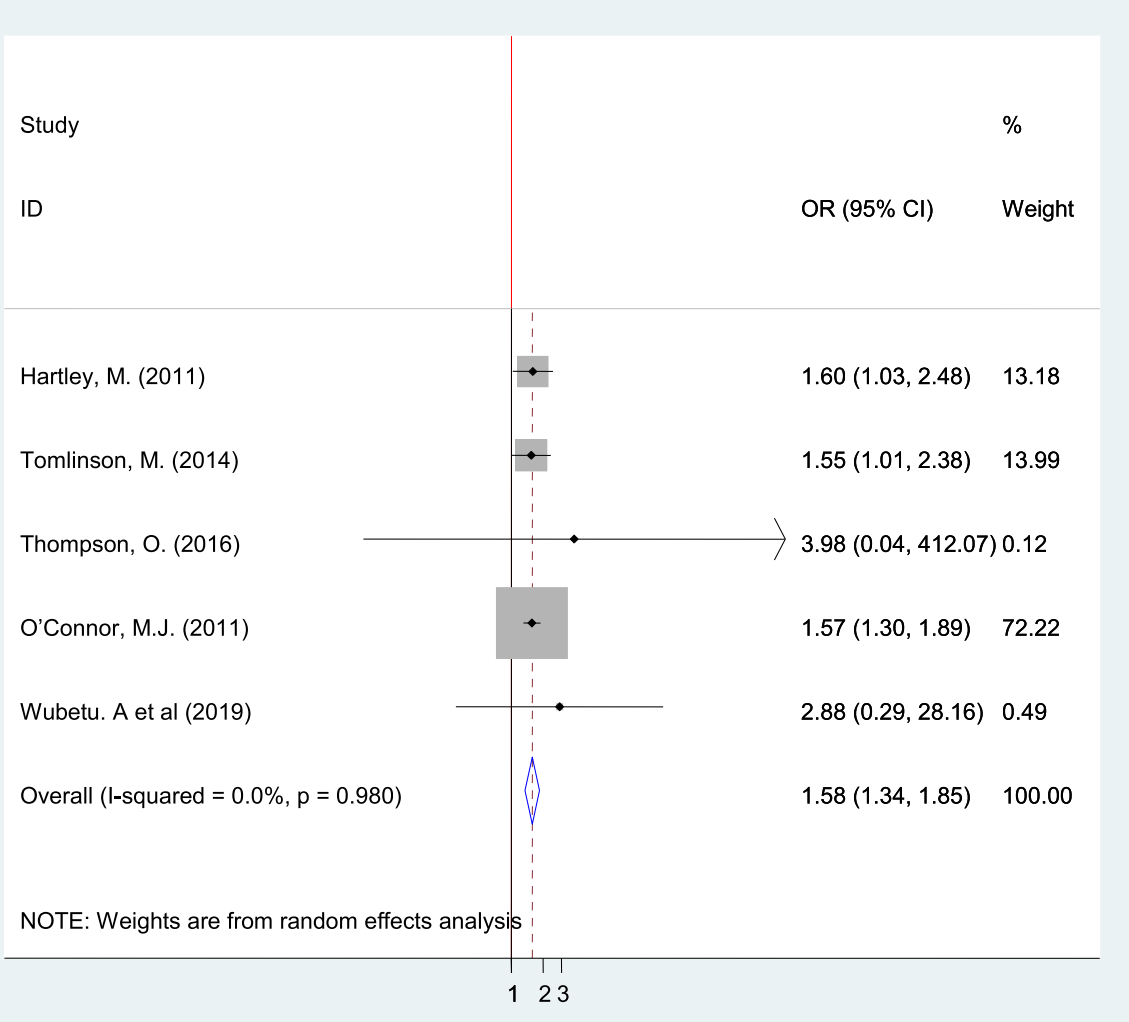

Fig. 6 The pooled odds ratio of the association between pregnant women alcohol consumption and depression in Sub-Saharan Africa

consumption have co-occurred in the same individual [79]. This might be attributable to some women drink alcohol as self-medication to detach from depression or depression might happen due to excessive alcohol use.

We observed a statistically significant association between partner's alcohol use and maternal alcohol intake during pregnancy in four studies [19-21, 63]. This result was consistent with a study conducted in San Diego [80]. The possible explanation was that married or cohabiting partners tend to have concordant alcohol and other substances use patterns. Moreover, unplanned pregnancy was found to be statistically risk factors for alcohol consumption in pregnant women. It was agreed with the study carried out in Korea [68]. The possible reason for this correlation might be the social and psychological impact of unplanned pregnancy that can have the potential to force pregnant women for the initiation of alcohol or other substance use to get relief from their stress [81]. Another significant factor that related to alcohol use was knowledge. It was found that women who knew that alcohol harms the fetus were less likely to consume alcohol during pregnancy. This finding was consistent with the studies conducted in Danish [82], $85 \%$ of respondents knew that alcohol is possibly harmful to the baby and in France [83], 83\% of respondents knew that alcohol in pregnancy could be harmful to the fetus and they less likely use alcohol.

Health care providers need to give compelling and brief counseling regarding strategies to avoid alcohol use in primary and prenatal care. Health care providers also should encourage drinking women to use effective contraceptive measures, therefore, it is important for reducing unplanned or unintended pregnancies. A Great effort should be done to enhance awareness of women about the adverse effect of alcohol drinking during pregnancy. The partners should be informed that the harmful effects of drinking alcohol during pregnancy and assist in achieving abstinence and support for women at risk are part of routine women's health care. Special advice has to be given for depressed pregnant women concerning mechanisms to abstain from alcohol consumption during pregnancy.

\section{The strength of the study}

A comprehensive search strategy and strict inclusion and exclusion criteria were used.

\section{The limitations of the study}

The magnitude of alcohol consumption during pregnancy might be underestimated because of self-reporting 
which could prone to social desirability and recall bias. Since different data collection tools were used in the primary studies, the tool could not measure or determine the result of the outcome in an equal manner. The authors calculated some figures from studies that were not directly written in the results; this might be unclear for readers. Besides, reports, unpublished studies, and grey literature were not included in this review.

\section{Conclusions}

The result showed that there was high alcohol consumption during pregnancy in Sub- Saharan Africa. Alcohol consumption during pregnancy was associated with depression, partners' alcohol use, unplanned pregnancy and knowledge of the harmful effects of alcohol consumption. Therefore, this will be a basis for public policy and resource allocation for prevention initiatives. Antenatal care providers should also assess these factors for improved detection of women at risk for alcoholexposed pregnancies and promote a healthy lifestyle that could be optimized. There is a need for a future study on the effect of consumption during pregnancy in SubSaharan Africa.

\section{Abbreviations}

ASSIST: Alcohol smoking and substance involvement test; AUDIT: Alcohol use disorders identification test; AUDIT-C: Alcohol use disorder identification testconsumption; CAGE: Cutting down, annoyance, guilt, and eye-opener; FAS: Fetal alcohol syndrome; FASD: Fetal alcohol spectrum disorder; JBI: Joanna Briggs Institute; PAE: Pregnancy alcohol exposure; PRISMA: Preferred reporting items for systematic review and meta-analysis statement; T-ACE: Tolerance- annoyed, cut off, eye-opening; TWEAK: Tolerance, worried, eye-opener, amnesia and, K/Cut-down

\section{Acknowledgments}

Not applicable.

\section{Authors' contributions}

AE conceptualized and wrote the original script. Both AE and GM participated in data extraction and together determined the methodology, validated, reviewed and edited the final manuscript. TA, YK, and MY commented on the script. All authors read and approved the final manuscript before submission.

\section{Funding}

Not applicable.

\section{Availability of data and materials}

All generated data during this review are included in this published article.

\section{Ethics approval and consent to participate}

Not applicable.

\section{Consent for publication}

Not applicable.

\section{Competing interests}

The authors declare that they have no competing interests.

\section{Author details}

${ }^{1}$ Department of Public Health, College of Medicine and Health Sciences, Wachemo University, Hossana, Ethiopia. ${ }^{2}$ Department of Epidemiology and Biostatistics, Institute of Public Health, College of Medicine and Health Sciences, University of Gondar, Gondar, Ethiopia. ${ }^{3}$ Department of Health
Promotion and Behavioral Sciences, Institute of Public Health, College of Medicine and Health Sciences, University of Gondar, Gondar, Ethiopia. ${ }^{4}$ Department of Health Systems and Policy, Institute of Public Health, College of medicine and health Sciences, University of Gondar, Gondar, Ethiopia. ${ }^{5}$ Department of Psychiatry, College of Medicine and Health sciences, Debre Tabor University, Debra Tabor, Ethiopia.

Received: 22 November 2019 Accepted: 23 March 2020

Published online: 15 April 2020

\section{References}

1. Asamoah BOAA. Alcohol consumption in relation to maternal deaths from induced-abortions in Ghana. Reprod Health. 2012;9(1):10.

2. Jones K, Smith D. Recognition of the fetal alcohol syndrome in early infancy. Lancet. 1973;302(7836):999-1001.

3. Patra J, Bakker R, Irving H, Jaddoe WW, Malini S, Rehm J. Dose-response relationship between alcohol consumption before and during pregnancy and the risks of low birthweight, preterm birth and small for gestational age (SGA) - a systematic review and meta-analyses. BJOG Int J Obstet Gynaecol. 2011;118(12):1411-21.

4. BabyCenter Medical Advisory Board. How much alcohol is too much during pregnancy? . 2016

5. CDC: Center for Diseases Control and prevention. Fetal alcohol spectrum Disorders (FASDs). https://www.cdc.gov/ncbddd/fasd/facts.html.

6. U. J: Alcohol and Pregnancy: Is 'A Little Bit' Safe? https://www.webmd.com/ baby/features/drinking-alcohol-during-pregnancy.

7. NHS: NHS Foundation Trust. Alcohol and pregnancy.

8. Chola L, Mutyambizi C, Sewpaul R, Parker WA, McHiza Z, Labadarios D, Hongoro C. Self-reported diabetes during pregnancy in the south African National Health and nutrition examination survey: extent and social determinants. BMC Pregnancy Childbirth. 2017;17(1):20

9. Sarah.: Is it safe to drink alcohol during pregnancy? https://www. essentialparent.com/lesson/is-it-safe-to-drink-alcohol-during-pregnancy-1 844/.

10. J. K: Light drinking during pregnancy does not harm unborn baby, study suggests. . Monday 11 September 2017. https://www.independent.co.uk/ news/health/pregnancy-drinking-units-allowed-health-baby-harm-a7941316. html.

11. Unit drinking alcohol while pregnant - NHS.UK. . Last reviewed: 14/01/2017. https://www.nhs.uk/conditions/pregnancy-and-baby/alcohol-medicinesdrugs-pregnant/.

12. C. S: Alcohol consumption during pregnancy: Results from the 2010 National Drug Strategy Household Survey. Foundation for alcohol research and Education; 2010.

13. Grum T, Seifu A, Abay M, Angesom T, Tsegay L. Determinants of preeclampsia/Eclampsia among women attending delivery Services in Selected Public Hospitals of Addis Ababa, Ethiopia: a case control study. BMC Pregnancy Childbirth. 2017:17(1):307.

14. WHO: World Health Organization (WHO). Global Information System on Alcohol and Health (GISAH). Geneva, Available from: http://apps.who.int/ gho-data/: WHO; 2014.

15. Popova S, Lange S, Probst C, Shield K, Kraicer-Melamed H, Ferreira-Borges C, Rehm J. Actual and predicted prevalence of alcohol consumption during pregnancy in the WHO African region. Tropical Med Int Health. 2016;21(10):1209-39.

16. WHO. Global status report on alcohol and health: WHO; 2014. https://apps. who.int/iris/bitstream/10665/112736/1/9789240692763_eng.pdf.

17. Abasiubong F, Bassey EA, Udobang JA, Akinbami OS, Udoh SB, Idung AU Self-Medication: potential risks and hazards among pregnant women in Uyo, Nigeria. Pan African Medical Journal. 2012;13(1).

18. Ordinioha B, Brisibe S. Alcohol consumption among pregnant women attending the ante. Natal clinic of a tertiary hospital in south. South Nigeria. Niger J Clin Pract. 2015;18(1):13-7.

19. Anteab K, Demtsu B, Megra M. Assessment of prevalence and associated factors of alcohol use during pregnancy among the dwellers of Bahir-Dar City, Northwest Ethiopia, 2014; 2014.

20. Morojele NK, London L, Olorunju SA, Matjila MJ, Davids AS, Rendall-Mkosi KM. Predictors of risk of alcohol-exposed pregnancies among women in an urban and a rural area of South Africa. Soc Sci Med. 2010;70(4):534-42.

21. Namagembe I, Jackson LW, Zullo MD, Frank SH, Byamugisha JK, Sethi AK. Consumption of alcoholic beverages among pregnant urban Ugandan women. Matern Child Health J. 2010;14(4):492-500. 
22. Hartley M, Tomlinson M, Greco E, Comulada WS, Stewart J, le Roux I, Mbewu N Rotheram-Borus MJ. Depressed mood in pregnancy: prevalence and correlates in two Cape Town peri-urban settlements. Reprod Health. 2011;8:9.

23. Moher D, Liberati A, Tetzlaff J, Altman DG. Preferred reporting items for systematic reviews and meta-analyses: the PRISMA statement. Ann Intern Med. 2009;151(4):264-9.

24. Worldbank: https://data.worldbank.org/region/sub-saharan-africa. 2018

25. Moola S, Munn Z, Tufanaru C, Aromataris E, Sears K, Sfetcu R, Currie M, Qureshi R, Mattis P, Lisy K. Chapter 7: systematic reviews of etiology and risk. In: Joanna Briggs Institute Reviewer's Manual The Joanna Briggs Institute; 2017.

26. Peters MD, Godfrey CM, Mclnerney P, Soares CB, Khalil H, Parker D. The Joanna Briggs institute reviewers' manual 2015: methodology for JBI scoping reviews; 2015.

27. Munn Z, Moola S, Lisy K, Riitano D, Tufanaru C. Methodological guidance for systematic reviews of observational epidemiological studies reporting prevalence and cumulative incidence data. Int J Evidence-based Healthcare. 2015;13(3):147-53.

28. Higgins JP, Thompson SG. Quantifying heterogeneity in a meta-analysis. Stat Med. 2002;21(11):1539-58.

29. Duval S, Tweedie R. Trim and fill: a simple funnel-plot-based method of testing and adjusting for publication bias in meta-analysis. Biometrics. 2000; 56(2):455-63.

30. Demelash H, Motbainor A, Nigatu D, Gashaw K, Melese A. Risk factors for low birth weight in bale zone hospitals, south-East Ethiopia: a case-control study. BMC Pregnancy Childbirth. 2015;15(1):264.

31. Endeshaw M, Abebe F, Bedimo M, Asart A. Diet and pre-eclampsia: a prospective multicentre case-control study in Ethiopia. Midwifery. 2015; 31(6):617-24.

32. Aboye W, Berhe T, Birhane T, Gerensea H. Prevalence and associated factors of low birth weight in Axum town, Tigray, North Ethiopia. BMC Res Notes. 2018;11(1):684

33. Taye M, Afework M, Fantaye W, Diro E, Worku A. Factors associated with congenital anomalies in Addis Ababa and the Amhara region, Ethiopia: a case-control study. BMC Pediatr. 2018;18(1):142.

34. Tessema GA, Tekeste A, Ayele TA. Preeclampsia and associated factors among pregnant women attending antenatal care in Dessie referral hospital, Northeast Ethiopia: a hospital-based study. BMC Pregnancy Childbirth. 2015;15(1):73.

35. Tefera TB, Erena AN, Kuti KA, Hussen MA. Perinatal depression and associated factors among reproductive aged group women at Goba and Robe Town of Bale Zone, Oromia Region, South East Ethiopia. Mater Health Neonatol Perinatol. 2015;1:12

36. Hanlon C, Medhin G, Alem A, Tesfaye F, Lakew Z, Worku B, Dewey M, Araya M, Abdulahi A, Hughes M. Impact of antenatal common mental disorders upon perinatal outcomes in Ethiopia: the P-MaMiE population-based cohort study. Tropical Med Int Health. 2009;14(2):156-66.

37. Mekuriaw B, Belayneh Z, Shemelise T, Hussen R. Alcohol use and associated factors among women attending antenatal care in southern Ethiopia: a facility based cross sectional study. BMC Res Notes. 2019;12(1):690.

38. Wubetu AD, Habte S, Dagne K. Prevalence of risky alcohol use behavior and associated factors in pregnant antenatal care attendees in Debre Berhan, Ethiopia, 2018. BMC Psychiatry. 2019;19(1):250.

39. Vythilingum B, Roos A, Faure SC, Geerts L, Stein DJ. Risk factors for substance use in pregnant women in South Africa. SAMJ: South African Medical Journal. 2012;102(11):853-4

40. Tomlinson M, O'Connor MJ, le Roux IM, Stewart J, Mbewu N, Harwood J, Rotheram-Borus MJ. Multiple risk factors during pregnancy in South Africa: the need for a horizontal approach to perinatal care. Prevent Sci. 2014;15(3):277-82.

41. Roos A, Geerts L, Koen N, Faure SC, Vythilingum B, Stein DJ. Psychosocial predictors of fetoplacental blood flow during pregnancy. Compr Psychiatry. 2015;57:125-31.

42. Onah MN, Field S, van Heyningen T, Honikman S. Predictors of alcohol and other drug use among pregnant women in a peri-urban south African setting. Int J Ment Heal Syst. 2016;10:38.

43. Budree S, Stein DJ, Brittain K, Goddard E, Koen N, Barnett W, Myer L, Zar HJ. Maternal and infant factors had a significant impact on birthweight and longitudinal growth in a South African birth cohort. Acta Paediatrica. 2017; 106(11):1793-801.

44. Myers B, Koen N, Donald KA, Nhapi RT, Workman L, Barnett W, Hoffman N, Koopowitz S, Zar HJ, Stein DJ. Effect of hazardous alcohol use during pregnancy on growth outcomes at birth: findings from a south African cohort study. Alcohol Clin Exp Res. 2017;42(2):369-77.

45. Petersen Williams P, Jordaan E, Mathews C, Lombard C, Parry CD. Alcohol and other drug use during pregnancy among women attending midwife obstetric units in the cape Metropole, South Africa. Adv Prevent Med. 2014; 2014:871427.

46. O'Connor MJ, Tomlinson M, Leroux IM, Stewart J, Greco E, Rotheram-Borus MJ. Predictors of alcohol use prior to pregnancy recognition among township women in Cape Town, South Africa. Soc Sci Med. 2011;72(1):83-90.

47. Onwuka Cl, Ugwu EO, Dim CC, Menuba IE, lloghalu El, Onwuka Cl. Prevalence and Predictors of Alcohol Consumption during Pregnancy in South-Eastern Nigeria. J Clin Diagnostic Res. 2016;10(9):Qc10-qc13.

48. Nyoyoko NP, Umoh AV. The prevalence and determinants of HIV seroconversion among booked ante natal clients in the University of Uyo teaching hospital, Uyo Akwa Ibom State, Nigeria. Pan African Med J. 2016; 25:247.

49. Thompson O, Ajayi I. Prevalence of antenatal depression and associated risk factors among pregnant women attending antenatal clinics in Abeokuta north local government area, Nigeria. Depression Res Treat. 2016;2016:4518979.

50. Adebowale OO, James BO. Psychoactive substance use and psychiatric morbidity among pregnant women attending an ante-natal clinic in Benin City, Nigeria. The Nigerian postgraduate medical journal. 2018;25(1):8-12.

51. Otupiri E, Nakua E, Tagbor H, Bonney AA, Edusei AK, Adusi-Poku Y. Pregnant women and alcohol use in the Bosomtwe District of the Ashanti regionGhana; 2012.

52. Da Pilma LJ, Dako-Gyeke P, Agyemang SA, Aikins M. Alcohol consumption among pregnant women in James town community, Accra, Ghana. Reprod Health. 2017;14(1):120

53. Wagura P, Wasunna A, Laving A, Wamalwa D, Ng'ang'a P. Prevalence and factors associated with preterm birth at kenyatta national hospital. BMC Pregnancy Childbirth. 2018;18(1):107.

54. Mosha TC, Philemon N. Factors influencing pregnancy outcomes in Morogoro municipality, Tanzania. Tanzania J Health Res. 2010;12(4):249-60.

55. Mpelo M, Kibusi SM, Moshi F, Nyundo A, Ntwenya JE, Mpondo BC. Prevalence and factors influencing alcohol use in pregnancy among women attending antenatal care in Dodoma region, Tanzania: a crosssectional study. Journal of pregnancy. 2018;2018.

56. Nombo AP, Mwanri AW, Brouwer-Brolsma EM, Ramaiya KL, Feskens EJM. Gestational diabetes mellitus risk score: a practical tool to predict gestational diabetes mellitus risk in Tanzania. Diabetes Res Clin Pract. 2018;145:130-7.

57. English L, Mugyenyi GR, Ngonzi J, Kiwanuka G, Nightingale I, Koren G, MacLeod S, Grunau BE, Wiens MO. Prevalence of ethanol use among pregnant women in southwestern Uganda. J Obstet Gynaecol Can. 2015; 37(10):901-2.

58. Sanou AS, Diallo AH, Holding P, Nankabirwa V, Engebretsen IMS, Ndeezi G, Tumwine JK, Meda N, Tylleskar T, Kashala-Abotnes E. Maternal alcohol consumption during pregnancy and child's cognitive performance at 6-8 years of age in rural Burkina Faso: an observational study. PeerJ. 2017;5:e3507.

59. Moise IK. Alcohol use, pregnancy and associated risk factors: a pilot crosssectional study of pregnant women attending prenatal care in an urban city. BMC Pregnancy Childbirth. 2019;19(1):472.

60. Williams AD, Nkombo Y, Nkodia G, Leonardson G, Burd L. Prenatal alcohol exposure in the Republic of the Congo: prevalence and screening strategies. Birth Defects Res A Clin Mol Teratol. 2013;97(7):489-96.

61. Lekettey JDP, Dako-Gyeke P, Agyemang SA, Aikins M. Alcohol consumption among pregnant women in James town community, Accra, Ghana. Reprod Health. 2017;14(1):120.

62. Barthélémy T-U, Andy MM, Roger MM. Effect of maternal alcohol consumption on gestational diabetes detection and mother-infant's outcomes in Kinshasa, DR Congo. Open J Obstet Gynecol. 2011;1(04):208.

63. Mpelo M, Kibusi SM, Moshi F, Nyundo A, Ntwenya JE, Mpondo BCT. Prevalence and factors influencing alcohol use in pregnancy among women attending antenatal Care in Dodoma Region, Tanzania: A CrossSectional Study. J Pregnancy. 2018;2018:8580318.

64. Jorgenson E, Thai KK, Hoffmann TJ, Sakoda LC, Kvale MN, Banda Y, Schaefer C, Risch N, Mertens J, Weisner C. Genetic contributors to variation in alcohol consumption vary by race/ethnicity in a large multi-ethnic genome-wide association study. Mol Psychiatry. 2017;22(9):1359-67.

65. Ferreira-Borges C, Esser MB, Dias S, Babor T, Parry CD. Alcohol control policies in 46 African countries: opportunities for improvement. Alcohol Alcohol. 2015;50(4):470-6. 
66. Tafere G. A review on traditional fermented beverages of Ethiopian. J Natural Sci Res. 2015;5:94-102.

67. May PA, Hamrick KJ, Corbin KD, Hasken JM, Marais AS, Blankenship J, Hoyme HE, Gossage JP. Maternal nutritional status as a contributing factor for the risk of fetal alcohol spectrum disorders. Reproductive toxicology. 2016:59:101-8.

68. Lee SH, Shin SJ, Won S-D, Kim E-J, Oh D-Y. Alcohol use during pregnancy and related risk factors in Korea. Psychiatry Investig. 2010;7(2):86-92.

69. Popova S, Lange S, Probst C, Gmel G, Rehm J. Estimation of national, regional, and global prevalence of alcohol use during pregnancy and fetal alcohol syndrome: a systematic review and meta-analysis. Lancet Glob Health. 2017;5(3)::290-9.

70. Denny CH, Acero CS, Naimi TS, Kim SY. Consumption of alcohol beverages and binge drinking among pregnant women aged 18-44 years-United States, 2015-2017. Morb Mortal Wkly Rep. 2019;68(16):365.

71. Grjibovski A, Bygren LO, Svartbo B. Socio-demographic determinants of poor infant outcome in north-West Russia. Paediatr Perinat Epidemiol. 2002; 16(3):255-62.

72. Kristjanson AF, Wilsnack SC, Zvartau E, Tsoy M, Novikov B. Alcohol use in pregnant and nonpregnant Russian women. Alcohol Clin Exp Res. 2007; 31(2):299-307.

73. Colvin L, Payne J, Parsons D, Kurinczuk JJ, Bower C. Alcohol consumption during pregnancy in nonindigenous west Australian women. Alcohol Clin Exp Res. 2007;31(2):276-84

74. Doherty E, Wiggers J, Wolfenden L, Anderson AE, Crooks K, Tsang TW, Elliott EJ, Dunlop AJ, Attia J, Dray J. Antenatal care for alcohol consumption during pregnancy: pregnant women's reported receipt of care and associated characteristics. BMC Pregnancy Childbirth. 2019;19(1):299.

75. Hutchinson D, Moore EA, Breen C, Burns L, Mattick RP. Alcohol use in pregnancy: prevalence and predictors in the $\mathrm{L}$ ongitudinal $\mathrm{S}$ tudy of a ustralian C hildren. Drug Alcohol Rev. 2013;32(5):475-82.

76. Henderson J, Gray R, Brocklehurst P. Systematic review of effects of lowmoderate prenatal alcohol exposure on pregnancy outcome. BJOG Int J Obstet Gynaecol. 2007;114(3):243-52.

77. Colombo R, Preve M, Bolla E, Traber R. Seasonal variation and alcohol consumption: a retrospective observational study. European Psychiatry. 2017:41:5874

78. Skagerstrom J, Chang G, Nilsen P. Predictors of drinking during pregnancy: a systematic review. J Women's Health. 2011;20(6):901-13.

79. Grant BF, Stinson FS, Dawson DA, Chou SP, Dufour MC, Compton W, Pickering RP, Kaplan K. Prevalence and co-occurrence of substance use disorders and independentmood and anxiety disorders: results from the national epidemiologic survey on alcohol and relatedconditions. Arch Gen Psychiatry. 2004;61(8):807-16.

80. Bakhireva LN, Wilsnack SC, Kristjanson A, Yevtushok L, Onishenko S, Wertelecki W, Chambers CD. Paternal drinking, intimate relationship quality, and alcohol consumption in pregnant Ukrainian women. J Stud Alcohol Drugs. 2011;72(4):536-44.

81. Connery HS, Albright BB, Rodolico JM. Adolescent substance use and unplanned pregnancy: strategies for risk reduction. Obstet Gynecol Clin. 2014;41(2):191-203.

82. Kesmodel U, Schiøler Kesmodel P. Drinking during pregnancy: attitudes and knowledge among pregnant Danish women, 1998. Alcohol Clin Exp Res. 2002;26(10):1553-60

83. Lelong N, Kaminski M, Chwalow J, Bean K, Subtil D. Attitudes and behavior of pregnant women and health professionals towards alcohol and tobacco consumption. Patient Educ Couns. 1995;25(1):39-49.

\section{Publisher's Note}

Springer Nature remains neutral with regard to jurisdictional claims in published maps and institutional affiliations.

Ready to submit your research? Choose BMC and benefit from:

- fast, convenient online submission

- thorough peer review by experienced researchers in your field

- rapid publication on acceptance

- support for research data, including large and complex data types

- gold Open Access which fosters wider collaboration and increased citations

- maximum visibility for your research: over $100 \mathrm{M}$ website views per year

At BMC, research is always in progress.

Learn more biomedcentral.com/submissions 